DR. MEHDI KABANI (Orcid ID : 0000-0001-7440-6394)

Article type : Research Article

\title{
Glucose availability dictates the export of the soluble and prion forms of Sup35p via periplasmic or extracellular vesicles
}

\author{
Mehdi Kabani*, Marion Pilard\# and Ronald Melki
}

Institut de Biologie François Jacob, Molecular Imaging Research Center (MIRCen), Commissariat à l'Energie Atomique et aux Energies Alternatives (CEA), Direction de la Recherche Fondamentale (DRF), Laboratoire des Maladies Neurodégénératives, Centre National de la Recherche Scientifique (CNRS), F-92265 Fontenay-aux-Roses

* Corresponding author: Mehdi.Kabani@cnrs.fr

\#present address: Université de Brest, GETBO EA3878, INSERM UMR 1078, UFR Médecine, 22 avenue Camille Desmoulins, F-29238 Brest, France.

This article has been accepted for publication and undergone full peer review but has not been through the copyediting, typesetting, pagination and proofreading process, which may lead to differences between this version and the Version of Record. Please cite this article as doi: $\underline{10.1111 / \mathrm{mmi} .14515}$

This article is protected by copyright. All rights reserved 


\section{Abstract}

The yeast $\left[\mathrm{PSI}^{+}\right]$prion originates from self-perpetuating transmissible aggregates of the translation termination factor Sup35p. We previously showed that infectious Sup35p particles are exported outside the cells via extracellular vesicles (EV). This finding suggested a function for EV in the vertical and horizontal transmission of yeast prions. Here we report a significant export of Sup35p within periplasmic vesicles (PV) upon glucose starvation. We show that PV are up to three orders of magnitude more abundant than EV. However, PV and EV are different in terms of size and protein content, and their export is oppositely regulated by glucose availability in the growth medium. Overall, our work suggests that the export of prion particles to both the periplasm and the extracellular space need to be considered to address the physiological consequences of vesiclemediated yeast prions trafficking.

Key words: SUP35, yeast, prion, $\left[\mathrm{PSI}^{+}\right]$, periplasmic vesicles, extracellular vesicles, glucose 


\section{Introduction}

Several 'proteinaceous infectious particles', or prions, are carried by the yeast Saccharomyces cerevisiae (reviewed in (Liebman and Chernoff, 2012)). The $\left[\mathrm{PSI}^{+}\right]$prion results from the assembly of the translation termination factor Sup35p into structurally distinct self-perpetuating fibrillar protein aggregates (Cox, 1965; Ter-Avanesyan et al., 1994; Patino et al., 1996; Paushkin et al., 1996; Glover et al., 1997; Tanaka et al., 2004; Krishnan and Lindquist, 2005; Toyama et al., 2007). Consequently, $\left[\mathrm{PSI}^{+}\right]$cells exhibit nonsense suppression phenotypes, the severity of which defines distinct 'strong' or 'weak' $\left[\mathrm{PSI}^{+}\right]$strains (Derkatch et al., 1996; Eaglestone et al., 1999; Liebman and Derkatch, 1999; Zhou et al., 1999; Uptain et al., 2001; Tanaka et al., 2004). Furthermore, $\left[\mathrm{PSI}^{+}\right]$variants have been proposed to be both advantageous (True and Lindquist, 2000; True et al., 2004; Tyedmers et al., 2008; Halfmann et al., 2012; Wang et al., 2017) or detrimental (McGlinchey et al., 2011; Wickner et al., 2011) to the cells.

$\left[\mathrm{PSI}^{+}\right]$is stably and faithfully transmitted from mother to daughter cells during cell division (Cox et al., 2003). The transformation of naïve cells by cytosolic fractions isolated from $\left[\mathrm{PSI}^{+}\right]$cells or by Sup35p fibrils formed in vitro efficiently induces the prion state in the recipient cells (King and Diaz-Avalos, 2004; Tanaka et al., 2004). Nonsense suppression of the ade1-14 allele in 'strong' or 'weak' $\left[\mathrm{PSI}^{+}\right]$cells following Sup35p aggregation leads to the formation of white or pink colonies on adenine-limiting media whereas [psi-] colonies are red (Chernoff et al., 1995). The presence of $\left[\mathrm{PSI}^{+}\right]$can also be monitored by the detection of SDS-resistant Sup35p polymers using semidenaturant detergent agarose gel electrophoresis (SDD-AGE), or by decorating pre-existing prion aggregates with Sup35-GFP fusions (Patino et al., 1996; Zhou et al., 2001; Mathur et al., 2010; Arslan et al., 2015; Sharma et al., 2017; Wang et al., 2019). However, these macroscopic manifestations of $\left[\mathrm{PSI}^{+}\right]$may not represent the transmissible prion particles, often referred to as 'propagons' (Cox et al., 2003; Wang et al., 2019). We have recently showed that infectious Sup35p particles are released in the extracellular space within extracellular vesicles (EV) which by virtue of their morphology and size $(\sim 30-100 \mathrm{~nm})$ have all the characteristic features of exosomes (Kabani and Melki, 2015). Following these observations, we proposed that vesicle-embedded prions could be efficient vectors for both vertical and horizontal transmission, as they meet all the requirements for propagons (Kabani and Melki, 2016). First, they contain the structural information needed for faithful prion propagation (Kabani and Melki, 2015). Second, they have a size and mobility which is compatible with a traffic from mother to daughter cell via the bud-neck 
(Derdowski et al., 2010; Kabani and Melki, 2015). Finally, they are shielded from the protein quality control machinery in place to prevent young cells from inheriting the damaged macromolecules and organelles of older mother cells (Tessarz et al., 2009; Liu et al., 2010; Zhou et al., 2011; Kabani and Melki, 2015; Kabani and Melki, 2016).

Achieving satisfactory yields of yeast EV for downstream experiments is time consuming and the isolation process is poorly suited for multiple samples analysis (Kabani and Melki, 2015). To further investigate the mechanisms and roles of yeast prions trafficking via EV therefore requires alternate experimental strategies.

It was previously shown that glucose starvation triggers the export of gluconeogenic enzymes in the periplasm of yeast (Alibhoy et al., 2012). Periplasmic gluconeogenic enzymes were shown to be associated to small vesicles, hereafter referred to as periplasmic vesicles (PV) (Giardina et al., 2014). It is not clear whether PV and EV represent the same entities, although their protein content partially overlaps (Oliveira et al., 2010a; Giardina et al., 2014).

In the present study, we show that Sup35p is massively exported in PV under glucose starvation conditions. The export of PV and EV is oppositely regulated in response to glucose starvation. While PV and EV share similar morphologies, they display significant differences in terms of size distribution and protein content. Our results support the use of PV as a fast and simple mean to investigate the mechanisms of packaging and export of yeast prions within membrane vesicles. The results we report here and those we obtained previously clearly suggest that both PV and EV should be taken into account when addressing the physiological roles of these vesicles in the propagation and transmission of yeast prions.

\section{Results}

\section{Isolation of periplasmic and extracellular vesicles from yeast cultures}

The isolation of EV from yeast cultures supernatants relies on filtration and ultracentrifugation steps (Fig. 1, right panel) (Kabani and Melki, 2015). This procedure allows the isolation of sufficient amounts of EV for biochemical, electron microscopy or functional assays (Kabani and Melki, 2015). However, achieving a satisfactory EV yield requires the processing of 1-2 L of yeast cultures, which is not only time consuming but also a major drawback for the analysis of multiple samples in parallel. Because they are readily extractable by the combined action of high $\mathrm{pH}$ and $\beta$ - 
mercaptoethanol (Alibhoy et al., 2012), we asked whether periplasmic vesicles would be a good alternative to analyze the vesicle-mediated export of yeast prions. To this end, PV were isolated (Fig. 1, left panel) from yeast cells grown for 3 days in normal (2\%) or limiting (0.5\%) glucose concentrations, and compared to EV isolated from the same cultures. Using their total protein content as a readout, we found that PV were on average $\sim 20$-times more abundant in cells starved for glucose than in cells grown in standard conditions (Fig. 2A). This is in agreement with previous reports suggesting that upon glucose starvation gluconeogenic enzymes are exported in the periplasm in association with periplasmic vesicles (Alibhoy et al., 2012; Giardina et al., 2013; Giardina et al., 2014). Unexpectedly however, yeast cells starved for glucose produced on average 20-times less EV than cells grown in standard conditions (Fig. 2A, inset). Regardless of growth conditions, PV were up to three orders of magnitude more abundant than EV (Fig. 2A). Thus, PV and EV may represent different populations of vesicles differentially exported in the periplasm and extracellular space in response to glucose availability. In support of this hypothesis and in agreement with previous proteomics data (Oliveira et al., 2010a; Giardina et al., 2014), the protein patterns of PV and EV assessed by SDS-PAGE are different (Fig. 2B), suggesting these two types of vesicles carry distinct cargos. As reported previously (Kabani and Melki, 2015), SDS-resistant Sup35p was found in EV isolated from $\left[\mathrm{PSI}^{+}\right]$cells grown in $2 \%$ glucose (Fig. 2B). Importantly, SDS-resistant Sup35p particles were also detected in PV isolated from $\left[\mathrm{PSI}^{+}\right]$cells grown in $2 \%$ or $0.5 \%$ glucose (Fig. 2B). This confirms that a subset of packaged proteins are common to PV and EV (Oliveira et al., 2010a; Giardina et al., 2014). The abundance of Sup35p in PV and EV was directly related to the respective abundance of both types of vesicles in the different growth conditions (Fig. 2A), with $\mathrm{PV}$ isolated from glucose-starved $\left[\mathrm{PSI}^{+}\right]$cells containing the highest amounts of SDS-resistant Sup35p particles (Fig. 2B). Taken together, these results establish PV as reservoir of aggregated Sup35p and justifies assessing their role in vesicle-mediated packaging and export of yeast prion particles.

\section{Large vesicles are more abundant in PV than in EV}

We next used transmission electron microscopy (TEM) to compare the morphologies and size distributions of PV and EV. Cup-shaped, round or ovoid vesicles were observed in both PV and EV preparations (Fig. 3), these morphologies being very similar to what we and others have 
previously reported for yeast EV (Oliveira et al., 2010a; Giardina et al., 2014; Kabani and Melki, 2015). The diameter of PV and EV ranged from $\sim 20 \mathrm{~nm}$ to $\sim 500 \mathrm{~nm}$ (Fig. 4A, total). The proportion of PV and EV with a small diameter $(<100 \mathrm{~nm})$, represented $76 \%$ and $85 \%$ of the vesicles, respectively (Fig. 4A, $<100 \mathrm{~nm}$ and Fig. 4B). The proportion of PV with a large diameter $(>100-500 \mathrm{~nm}$ ) was higher than that of EV (Fig. 4A, >100 $\mathrm{nm}$ ). Indeed, vesicles with a large diameter, ranging from 200 to $600 \mathrm{~nm}$, represented $\sim 12 \%$ of PV but only $\sim 4 \%$ of EV (Fig. 4B). These results are in agreement with previous reports (Giardina et al., 2014; Kabani and Melki, 2015). The reasons behind these apparent vesicle size differences remain to be determined. They could result from: $i$ ) differences in the vesicles subcellular origin and biogenesis; $i$ ) the membrane and/or cell wall sorting of vesicles based on their size; iii) the selective regulation of vesicles export and import, such as the rapid endocytosis of small vesicles observed when starved cells are replenished in glucose (Giardina et al., 2014). With respect to the latter, it should be noted that we did not observe significant differences in the respective size distributions of PV and EV isolated from cells grown in $2 \%$ or $0.5 \%$ glucose (Fig. S1).

\section{Sup35p is massively exported into periplasmic vesicles in glucose starved yeast cells}

Next, time course experiments were conducted to gain further insight into the export of Sup $35 \mathrm{p}$ in the periplasm. Exponentially growing $\left[\mathrm{psi}^{-}\right],\left[\mathrm{PSI}^{+}\right]^{\mathrm{S}}$ and $\left[\mathrm{PSI}^{+}\right]^{\mathrm{W}} 74-\mathrm{D} 694$ cells were inoculated into YPDA medium containing $2 \%$ or $0.5 \%$ glucose (Fig. 5). Cells grew slightly slower in $0.5 \%$ than in $2 \%$ glucose during the exponential phase, but all cultures achieved similar cell densities after $24 \mathrm{~h}$ of growth (Fig. S2). Aliquots were taken at increasing time intervals and intracellular (I) and total periplasmic $\left(\mathrm{P}^{\mathrm{T}}\right)$ fractions were prepared using the procedure presented in Fig. 1 (left panel). As shown in Fig. 5, both the monomeric and SDS-resistant forms of Sup35p were gradually exported into the periplasm after $24 \mathrm{~h}$ of culture in glucose-starved cells. Sup $35 \mathrm{p}$ was not detected in the periplasm extracted from cells grown in $2 \%$ glucose (Fig. 5). The apparent discrepancy with the data presented in Fig. 2B, where Sup35p is detected in the periplasm of cells grown in $2 \%$ glucose, is simply due to different amount of cells processed in each type of experiment (e.g. $1200 \mathrm{OD}_{600 \mathrm{~nm}}$ units in Fig. $2 \mathrm{~B}$ and $20 \mathrm{OD}_{600 \mathrm{~nm}}$ units in Fig. 5). As expected from earlier studies, Pgk1p and Hsp70 were also exported into the periplasm of glucose-starved cells albeit each with slightly different kinetics (Fig. 5) (Giardina et al., 2014; Kabani and Melki, 2015). 
Additionally, the intracellular levels of Sup35p were $\sim$ twofold lower in glucose-starved cells during the exponential phase (6h-timepoint), and decreased upon entry into diauxic and early stationary phases of growth in agreement with previous data (Wang et al., 2019) (Fig. 5). As reported recently (Wang et al., 2019), the size of intracellular SDS-resistant Sup35p particles resolved by SDD-AGE decreased past the diauxic-shift (Fig. 5). Interestingly, in glucose-starved $\left[\mathrm{PSI}^{+}\right]$cells, the size of intracellular SDS-resistant Sup35p particles initially decreased after $24 \mathrm{~h}$ of cultures, but increased back to initial size after $48 \mathrm{~h}$ of cultures (Fig. 5). A similar behavior was previously observed only after 7 days of cultures in cells grown in $2 \%$ glucose, confirming that the remodeling of Sup35p aggregates during growth is governed by the physiological and metabolic state of the cells (Kryndushkin et al., 2003; Newnam et al., 2011; Wang et al., 2019). The size of SDS-resistant Sup35p particles in the periplasmic fraction was similar to that observed in the intracellular fraction of exponentially growing $\left[\mathrm{PSI}^{+}\right]$cells (Fig. 5). This observation supports our hypothesis that the packaging of Sup35p inside vesicles occurs during the exponential phase of growth (Kabani and Melki, 2015). We and others previously showed that Sup35p prion particles differ in size in $\left[\mathrm{PSI}^{+}\right]^{\mathrm{S}}$ and $\left[\mathrm{PSI}^{+}\right]^{\mathrm{W}}$ cells (Kryndushkin et al., 2003; Kabani et al., 2011; Kabani and Melki, 2015; Wang et al., 2019). The data presented in Fig. 5 suggest that the size of Sup35p prion particles did not affect their packaging into vesicles upon glucose starvation.

In order to further confirm that Sup35p prion particles are associated with $\mathrm{PV},\left[\mathrm{PSI}^{+}\right]^{\mathrm{S}}$ cells were cultivated in $0.5 \%$ glucose for 3 days, and intracellular and periplasmic fractions were obtained as described in Fig. 1. Periplasmic vesicles were recovered from the periplasmic fraction by ultracentrifugation (Fig. 1, left panel) and all fractions were analyzed by SDD-AGE (Fig. 5A). As described above, SDS-resistant Sup35p particles were massively exported into the periplasm of glucose-starved cells (Fig. 6A). Upon ultracentrifugation at 100,000 g, Sup35p particles were detected only in the PV fraction, but not in the supernatant (Fig. 6A, PS fraction). Immunogold labeling and electron microscopy revealed the presence of Sup35p inside Triton X-100permeabilized PV (Fig. 6B). PV were not stained by the secondary gold-conjugated antibody in the absence of primary anti-Sup35p antibodies, confirming that the immunogold labeling was specific for Sup35p (data not shown).

We previously showed that Sup35p prion particles packaged within EV in $\left[\mathrm{PSI}^{+}\right]$cells retained their infectivity in protein transformation assays (Kabani and Melki, 2015). Similarly, PV isolated from glucose-starved $\left[\mathrm{PSI}^{+}\right]$cells, but not from $\left[\mathrm{psi}^{-}\right]$cells, were able to confer the prion state 
when transformed into [psi-] 74-D694 spheroplasts, indicating that PV-associated Sup35p prion particles are infectious (Fig. S3).

Both a high $\mathrm{pH}$ and the presence of $\beta$-mercaptoethanol were required for the extraction of periplasmic proteins from glucose-starved cells (data not shown). Importantly, these experimental conditions were shown to prevent cell lysis (Cleves et al., 1996). To further ascertain that the release of Sup35p into the periplasmic fraction is not artificially due to the cell extraction procedure, we used a lyticase treatment to digest the cell wall and release the periplasmic content (Fig. S4A). The latter was then subjected to ultracentrifugation at $100,000 \mathrm{~g}$ to recover intact PV that were visualized by negative-stain electron microscopy (Fig. S4B). We show that Sup35p and Pgk1p are both detected in the PV fraction when cells were treated with lyticase but not when lyticase was omitted (Fig. S4C). In agreement with our previous experiments (Fig. 2), higher amounts of Sup35p and Pgk1p were recovered from the periplasm of glucose-starved cells than from cells grown in standard conditions (Fig. S4C). Thus, Sup35p is packaged inside vesicles and exported into the periplasm or the extracellular medium in a cell physiological and metabolic state-dependent manner.

\section{The export of Sup $35 p$ into the periplasm does not affect $\left[\mathrm{PSI}^{+}\right]$propagation}

The experiments presented in Fig. 5 show that substantial amounts of Sup35p are relocated to the periplasm upon glucose starvation. Yeast cells can survive with very low amounts of Sup35p (Chabelskaya et al., 2004; Wang et al., 2017; Wang et al., 2019), but the reduction of intracellular Sup35p levels could in principle affect the propagation of $\left[\mathrm{PSI}^{+}\right]$by modifying the equilibrium between soluble and aggregated species.

We then used a standard color-based assay to assess the effect of glucose starvation on $\left[\mathrm{PSI}^{+}\right]$ prion propagation (Chernoff et al., 1995). Indeed, an ade1-14 nonsense mutation causes 74-D694 [psi $i^{-}$cells to be red on adenine-limiting medium (1/4-YPD), due to the accumulation of a metabolite of the adenine biosynthetic pathway (Fig. 7, 2\% glucose). In contrast, 74-D694 $\left[\mathrm{PSI}^{+}\right]^{\mathrm{S}}$ and $\left[\mathrm{PSI}^{+}\right]^{\mathrm{W}}$ cells display light pink and dark pink, respectively, in agreement with their different nonsense suppression levels (Zhou et al., 1999; Uptain et al., 2001) (Fig. 7, 2\% glucose)..When grown on glucose-limiting plates, the colors of all strains shifted towards lighter colors: $\left[\mathrm{psi}^{-}\right]$cells 
shifted from red to dark pink, $\left[P S I^{+}\right]^{\mathrm{S}}$ from light pink to white and $\left[P S I^{+}\right]^{\mathrm{W}}$ from dark pink to light pink (Fig. 7, 0.5\% glucose). These data suggest that glucose starvation causes Sup35p export into the periplasm resulting in an apparent increase in nonsense suppression levels, regardless of whether the cells carry the prion or not. However, glucose starvation did not alter the prion phenotypes of $\left[\mathrm{PSI}^{+}\right]^{\mathrm{S}}$ and $\left[\mathrm{PSI}^{+}\right]^{\mathrm{W}}$ strains or cause prion loss, as both prion strains were stably and faithfully propagated (Fig. 7, 0.5\% glucose and data not shown).

\section{Discussion}

That yeast cells are filled with trafficking vesicles is known for more than half a century (Matile et al., 1971; Palade, 1975; Novick and Schekman, 1979). However, the ability of yeasts to secrete extracellular vesicles was a recent and unexpected discovery, as the cell wall was thought to be an impenetrable barrier for such large objects (Rodrigues et al., 2007; Albuquerque et al., 2008; Oliveira et al., 2010b; Wolf and Casadevall, 2014). Contrary to this initial assumption, the cell wall displays elastic properties that can be modulated by temperature, cell wall remodeling enzymes or aging (Pelling et al., 2004; Walker et al., 2018; Zhao et al., 2019). Therefore, EV could in principle cross the cell wall not only to exit the cells but also to penetrate and deliver their cargo within recipient cells (Kabani and Melki, 2016; Reis et al., 2019; Zhao et al., 2019). Given that infectious Sup35p particles were found in EV, we hypothesized that the latter could mediate the horizontal transfer of prions (Kabani and Melki, 2015; Kabani and Melki, 2016).

A major hindrance for more thorough investigations on the biogenesis and physiological roles of EV in yeast is that the amount of EV produced by a yeast culture is very low, which makes their isolation tedious (Kabani and Melki 2015). Rodrigues and colleagues recently proposed an EV isolation protocol based on yeast cells grown at high density on solid medium (Reis et al., 2019). This protocol allows the processing of multiple samples at once and EV isolation by ultracentrifugation is faster due to the lower volumes recovered after washing the cells with buffer (Reis et al., 2019). The EV yields, in terms of total EV proteins, were however not determined and cannot be easily compared to the ones achieved using ultracentrifugation of conditioned medium (Kabani and Melki, 2015). Here, we tried a different approach by asking whether periplasmic vesicles, which are trapped between the plasma membrane and the cell wall, could be used in lieu of EV. As previously described (Giardina et al., 2014), we found that PV are abundantly exported 
within the periplasm of glucose-starved cells (Fig. 2). Because PV are up to three orders of magnitude more abundant that EV (Fig. 2), we were able to isolate large amounts of these vesicles starting from a much smaller volume of cell culture (Fig. 1 and Fig. 2). Isolating PV is a straightforward process (Fig. 1, left panel) perfectly suitable for analyzing multiple samples. PV are morphologically undistinguishable from EV (Fig. 3) but they are significantly enriched in larger vesicles ( 200-500 nm) compared to EV (Fig. 4B and 4C). A simple explanation to account for this difference is that large vesicles cannot cross the cell wall barrier, although differences in the subcellular origin or biogenesis of PV and EV cannot be excluded. That PV and EV represent different populations of vesicles is supported by their different protein content, even when cells were grown in the same medium, and by their opposite regulation by glucose availability in the growth medium (Fig. 2).

Sup35p is exported within both types of vesicles (Fig. 2B and Fig. 5), suggesting a common packaging mechanism which appears to occur in actively dividing cells (Fig. 5) (Kabani and Melki, 2015) and might involve intracellular vesicle clusters (Winters et al., 2020). The size of Sup35p prion particles does not affect their packaging into vesicles (compare $\left[\mathrm{PSI}^{+}\right]^{\mathrm{S}}$ and $\left[\mathrm{PSI}^{+}\right]^{\mathrm{W}}$ cells in Fig. 5). The amounts of Sup35p that are retrieved in PV or EV are correlated to the amounts of vesicles exported (Fig. 2 and Fig. 5).

One function attributed to PV is the export of gluconeogenic enzymes in glucose-starved cells (Alibhoy et al., 2012; Giardina and Chiang, 2013; Giardina et al., 2014). When cells are replenished in glucose, these enzymes are rapidly internalized and degraded by the proteasome or the vacuole depending on the duration of glucose starvation (Hung et al., 2004; Giardina et al., 2014). By virtue of the enzymes they carry, yeast EV were recently shown to play important roles in cell wall remodeling and protection against antifungal agents (Zhao et al., 2019). From these examples, we hypothesize that Sup35p export in PV and EV might fulfill a physiological role. Here, it is important to separate the translation termination and prion properties of Sup $35 \mathrm{p}$. Indeed, both the soluble and prion forms of Sup35p are exported via PV and EV (Fig. 2 and Fig. 5) (Kabani and Melki, 2015). Periplasmic Sup35p levels were higher than their intracellular counterparts in glucose starved cells (Fig. 5). Sup35p export into the periplasm may allow the cells to fine-tune translation to adjust to their environmental conditions. In agreement with this hypothesis, other components of the translation machinery were identified both in PV and EV (Oliveira et al., 2010a; Giardina et al., 2014). It is yet unclear whether native and aggregated Sup35p are packaged within vesicles using the same or distinct mechanisms. Furthermore, other 
supramolecular assemblies of Sup35p, such as the bimolecular condensates which are formed under pH stress (Franzmann et al., 2018), may also be exported via these vesicles. By hijacking the PV-mediated protein export, Sup35p prion particles may escape protein quality control and clearance mechanisms (Tessarz et al., 2009; Liu et al., 2010; Zhou et al., 2011; Kabani and Melki, 2016). We were not able to observe the reinternalization of Sup35p upon glucose replenishing within the time frame of our experiments (data not shown), but vesicle trafficking back and forth via the periplasm would be an efficient mechanism for vertical prion propagation, as we previously hypothesized (Kabani and Melki, 2016). Furthermore, the EV-mediated horizontal transmission of Sup35p prion particles (Kabani and Melki, 2016) is further supported by recent experiments suggesting uptake of EV by yeast cells (Zhao et al., 2019).

Future studies are clearly needed to document the biogenesis and content of periplasmic and extracellular vesicles and whether these are composed of distinct, overlapping or identical vesicle populations. How environmental conditions modulate the production, protein content and differential export of EV and PV will be of essence to better understand their physiological roles, not only in the vertical and horizontal transmission of fungal prions, but also in yeast adaptation to environmental cues and intra- and inter-species communication.

\section{Materials and Methods}

Yeast strains, growth media and monitoring of prion phenotypes

The $S$. cerevisiae strains used in this study were derived from 74-D694 [MATa ade1-14 (UGA) trp1-289 leu2-3,112 his34-200 ura3-52]. When indicated, these strains carried strong $\left(\left[\mathrm{PSI}^{+}\right]^{\mathrm{S}}\right)$ or weak $\left(\left[\mathrm{PSI}^{+}\right]^{\mathrm{W}}\right)\left[\mathrm{PSI}^{+}\right]$prion variants, or no prion $\left(\left[p s i^{-}\right]\right)$. Yeast cells were grown in YPDA medium ( $1 \%$ yeast extract, $2 \%$ peptones, $2 \%$ glucose, $0.002 \%$ adenine). For glucose starvation conditions, YPDA medium contained only $0.5 \%$ glucose. Solid media contained $2 \%$ bacto-agar. For yeast cultures, a starter culture was obtained by growing cells overnight in YPDA containing $2 \%$ glucose under agitation at $30^{\circ} \mathrm{C}$. Starter cultures were then diluted at least 20 -fold (at an initial optical density at $600 \mathrm{~nm}$ of 0.1 ) into fresh medium containing the desired glucose concentration and cells were allowed to grow under agitation at $30^{\circ} \mathrm{C}$. Prion phenotypes were monitored on $1 / 4-$ YPD medium $(0.25 \%$ yeast extract, $2 \%$ peptones, $2 \%$ glucose $)$ via a standard color-based phenotype assay, as described before (Kabani et al., 2011; Kabani et al., 2014).

This article is protected by copyright. All rights reserved 


\section{Cell fractionation and isolation of periplasmic and extracellular vesicles}

Isolation of yeast EV by ultracentrifugation of extracellular medium was performed exactly as described before (Kabani and Melki, 2015) (Fig. 1, right panel). For PV isolation (Fig. 1, left panel), yeast cells were recovered by centrifugation at $3000 \mathrm{~g}$, washed once in water and then resuspended in extraction buffer $(100 \mathrm{mM}$ Tris.Cl $\mathrm{pH} 9.4,10 \mathrm{mM} \beta$-mercaptoethanol) at a cell density of approximately $100 \mathrm{OD}_{600 \mathrm{~nm}}$ units $/ \mathrm{mL}$. After a 15 min incubation at $37^{\circ} \mathrm{C}$ in a water bath, the extracted cells were separated from the total periplasm $\left(\mathrm{P}^{\mathrm{T}}\right)$ fraction by centrifugation for $5 \mathrm{~min}$ at $3000 \mathrm{~g}$. The extracted cell pellets were washed once in water, resuspended in one $\mathrm{P}^{\mathrm{T}}$ volume of lysis buffer $(100 \mathrm{mM}$ Tris.Cl pH 7.5, $50 \mathrm{mM} \mathrm{KCl,} 10 \mathrm{mM} \beta$-mercaptoethanol, $1 \mathrm{mM}$ PMSF and protease inhibitor cocktail, Roche Diagnostics) and then lysed by glass-beads beating as described before (Wang et al., 2017; Wang et al., 2019) to obtain the intracellular (I) fraction. For time course experiments, cell aliquots were treated with $10 \mathrm{mM}$ sodium azide on ice and recovered by centrifugation at $3000 \mathrm{~g}$. The cell pellets were then flash frozen in liquid nitrogen and kept at $-80^{\circ} \mathrm{C}$. All samples were then thawed in extraction buffer at a cell density of approximately $100 \mathrm{OD}_{600 \mathrm{~nm}}$ units/mL and processed in parallel as described above to obtain $\mathrm{P}^{\mathrm{T}}$ and I fractions. The $\mathrm{P}^{\mathrm{T}}$ fraction was filtered through a $0.2 \mu \mathrm{m}$ membrane (Millipore) and centrifuged for $70 \mathrm{~min}$ at $100,000 \mathrm{~g}$ and at $4^{\circ} \mathrm{C}$. The pellet containing the PV was washed with cold PBS, and the vesicles pelleted by ultracentrifugation at $100,000 \mathrm{~g}$ and at $4^{\circ} \mathrm{C}$. PV were then resuspended in PBS, aliquoted and flash-frozen in liquid nitrogen, and then stored at $-80^{\circ} \mathrm{C}$ until use. Protein concentrations of PV and EV preparations were determined by the Bradford protein assay according to the manufacturer's instructions (Bio-Rad).

\section{Electron microscopy and immunogold labeling}

Samples were processed for negative-stained transmission electron microscopy and immunogold labeling exactly as described before (Kabani and Melki, 2015). Images were acquired on an Jeol 1400 TEM, recorded with a Gatan Orius CCD camera (Gatan, Pleasanton, CA) and processed with the Image J software $(\mathrm{NIH})$. 
Western blots, dot blots and semi-denaturant detergent agarose gel electrophoresis (SDD-AGE) analyses

These assays were performed essentially as described previously (Kabani et al., 2011; Kabani et al., 2014; Kabani and Melki, 2015; Wang et al., 2019). Immunoblots were developed using enhanced chemiluminescence reagents (Pierce) and a Chemidoc imaging system (Biorad).

Induction of $\left[\mathrm{PSI}^{+}\right]$by transformation of yeast spheroplasts

Yeast 74-D694 [psi-] cells were converted to spheroplasts by lyticase treatment and then transformed with intact PV $(\sim 10 \mu \mathrm{g}$ protein $)$ in the presence of $100 \mu \mathrm{g} \cdot \mathrm{ml}^{-1}$ salmon sperm DNA and $20 \mu \mathrm{g} \cdot \mathrm{ml}^{-1}$ of the URA3-based pRS316 plasmid, as described before (Kabani et al., 2011; Kabani et al., 2014; Kabani and Melki, 2015). Mock transformation reactions lacking spheroplasts and/or pRS316 ensured that no viable cells remained in the PV preparations and the absence of spontaneous $\left[\mathrm{ura}^{+}\right]$revertants.

\section{Acknowledgements}

We thank Tracy Bellande for excellent technical assistance and Axelle Koreki for participating to the early stages of this study. M.K. and R.M. are supported by the Centre National de la Recherche Scientifique (CNRS). This work has benefited from the Imagerie-Gif core facility of the Institute for Integrative Biology of the Cell (I2BC), which is supported by the Agence Nationale de la Recherche (ANR-11-EQPX-0029/Morphoscope, ANR-10-INBS-04/FranceBioImaging ; ANR-11-IDEX-0003-02/ Saclay Plant Sciences ). All the data generated by this work are presented in this paper.

This article is protected by copyright. All rights reserved 


\section{References}

Albuquerque, P.C., Nakayasu, E.S., Rodrigues, M.L., Frases, S., Casadevall, A., ZancopeOliveira, R.M., et al. (2008) Vesicular transport in Histoplasma capsulatum: an effective mechanism for trans-cell wall transfer of proteins and lipids in ascomycetes. Cell Microbiol 10: 1695-1710 http://www.ncbi.nlm.nih.gov/pubmed/18419773.

Alibhoy, A.A., Giardina, B.J., Dunton, D.D., and Chiang, H.L. (2012) Vps34p is required for the decline of extracellular fructose-1,6- bisphosphatase in the vacuole import and degradation pathway. J Biol Chem 287: 33080-33093 http://www.ncbi.nlm.nih.gov/pubmed/22833678.

Arslan, F., Hong, J.Y., Kanneganti, V., Park, S.-K., and Liebman, S.W. (2015) Heterologous Aggregates Promote De Novo Prion Appearance via More than One Mechanism. PLoS Genet 11: e1004814 http://www.ncbi.nlm.nih.gov/pubmed/25568955. Accessed September 20, 2017.

Chabelskaya, S., Kiktev, D., Inge-Vechtomov, S., Philippe, M., and Zhouravleva, G. (2004) Nonsense mutations in the essential gene SUP35 of Saccharomyces cerevisiae are non-lethal. Mol Genet Genomics .

Chernoff, Y.O., Lindquist, S.L., Ono, B., Inge-Vechtomov, S.G., and Liebman, S.W. (1995) Role of the chaperone protein Hsp104 in propagation of the yeast prion-like factor [psi+]. Science (80-) 268: $880-884$

http://www.ncbi.nlm.nih.gov/entrez/query.fcgi?cmd=Retrieve \&db=PubMed\&dopt=Citation\&list_ uids $=7754373$.

Cleves, A.E., Cooper, D.N.W., Barondes, S.H., and Kelly, R.B. (1996) A new pathway for protein export in Saccharomyces cerevisiae. J Cell Biol .

Cox, B., Ness, F., and Tuite, M. (2003) Analysis of the generation and segregation of propagons: entities that propagate the $[\mathrm{PSI}+]$ prion in yeast. Genetics 165: 23-33 http://www.ncbi.nlm.nih.gov/pubmed/14504215. Accessed September 20, 2017.

Cox, B.S. (1965) PSI, a cytoplasmic suppressor of super-supressor in yeast. Heredity (Edinb) 20 : $505-521$.

Derdowski, A., Sindi, S.S., Klaips, C.L., DiSalvo, S., and Serio, T.R. (2010) A Size Threshold 
Limits Prion Transmission and Establishes Phenotypic Diversity. Science (80- ) 330: 680-683 http://www.sciencemag.org/cgi/doi/10.1126/science.1197785.

Derkatch, I.L., Chernoff, Y.O., Kushnirov, V. V., Inge-Vechtomov, S.G., and Liebman, S.W. (1996) Genesis and variability of [PSI] prion factors in Saccharomyces cerevisiae. Genetics 144: 1375-1386 http://www.ncbi.nlm.nih.gov/pubmed/8978027.

Eaglestone, S.S., Cox, B.S., and Tuite, M.F. (1999) Translation termination efficiency can be regulated in Saccharomyces cerevisiae by environmental stress through a prion-mediated

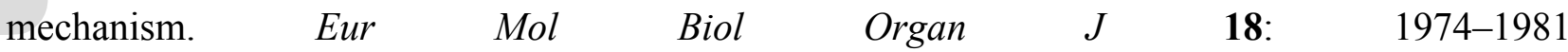
http://www.ncbi.nlm.nih.gov/entrez/query.fcgi?cmd=Retrieve \&db=PubMed\&dopt=Citation\&list uids $=10202160$.

Franzmann, T.M., Jahnel, M., Pozniakovsky, A., Mahamid, J., Holehouse, A.S., Nüske, E., et al. (2018) Phase separation of a yeast prion protein promotes cellular fitness. Science (80- ) 359: eaao5654 http://www.ncbi.nlm.nih.gov/pubmed/29301985. Accessed June 15, 2018.

Giardina, B.J., and Chiang, H.L. (2013) The key gluconeogenic enzyme fructose-1,6bisphosphatase is secreted during prolonged glucose starvation and is internalized following glucose re-feeding via the non-classical secretory and internalizing pathways in Saccharomyces cerevisiae. Plant Signal Behav 8 http://www.ncbi.nlm.nih.gov/pubmed/23673352.

Giardina, B.J., Dunton, D., and Chiang, H.L. (2013) Vid28 protein is required for the association of vacuole import and degradation (Vid) vesicles with actin patches and the retention of Vid vesicle proteins in the intracellular fraction. $J$ Biol Chem 288: 11636-11648 http://www.ncbi.nlm.nih.gov/pubmed/23393132.

Giardina, B.J., Stein, K., and Chiang, H.-L. (2014) The endocytosis gene END3 is essential for the glucose-induced rapid decline of small vesicles in the extracellular fraction in Saccharomyces $\begin{array}{lllll}\text { cerevisiae. } & J & \text { Extracell } & \text { vesicles } & \text { 3: }\end{array}$ http://www.journalofextracellularvesicles.net/index.php/jev/article/view/23497\%5Cnhttp://www.n cbi.nlm.nih.gov/pubmed/24665361\%5Cnhttp://www.pubmedcentral.nih.gov/articlerender.fcgi?arti $\mathrm{d}=$ PMC3963178.

Glover, J.R., Kowal, A.S., Schirmer, E.C., Patino, M.M., Liu, J.J., and Lindquist, S. (1997) Self- 
seeded fibers formed by Sup35, the protein determinant of [PSI+], a heritable prion-like factor of S. cerevisiae. Cell 89: 811-819 http://www.ncbi.nlm.nih.gov/pubmed/9182769.

Halfmann, R., Jarosz, D.F., Jones, S.K., Chang, A., Lancaster, A.K., and Lindquist, S. (2012) Prions are a common mechanism for phenotypic inheritance in wild yeasts. Nature 482: 363-368 http://www.ncbi.nlm.nih.gov/entrez/query.fcgi? $\mathrm{cmd}=$ Retrieve $\& \mathrm{db}=\mathrm{PubMed} \& \mathrm{dopt}=\mathrm{Citation} \&$ list uids $=22337056$.

Hung, G.C., Brown, C.R., Wolfe, A.B., Liu, J., and Chiang, H.L. (2004) Degradation of the gluconeogenic enzymes fructose-1,6-bisphosphatase and malate dehydrogenase is mediated by distinct proteolytic pathways and signaling events. J Biol Chem .

Kabani, M., Cosnier, B., Bousset, L., Rousset, J.P., Melki, R., and Fabret, C. (2011) A mutation within the C-terminal domain of Sup35p that affects [PSI+] prion propagation. Mol Microbiol 81: $640-658$.

Kabani, M., and Melki, R. (2015) Sup35p in its soluble and prion states is packaged inside extracellular vesicles. MBio 6.

Kabani, M., and Melki, R. (2016) More than just trash bins? Potential roles for extracellular vesicles in the vertical and horizontal transmission of yeast prions. Curr Genet $\mathbf{6 2}$.

Kabani, M., Redeker, V., and Melki, R. (2014) A role for the proteasome in the turnover of sup35p and in [PSI+] prion propagation. Mol Microbiol 92: 507-528.

King, C.Y., and Diaz-Avalos, R. (2004) Protein-only transmission of three yeast prion strains. Nature 428: 319-323 http://www.ncbi.nlm.nih.gov/pubmed/15029195.

Krishnan, R., and Lindquist, S.L. (2005) Structural insights into a yeast prion illuminate nucleation and strain diversity.

Nature

435:

$765-772$ http://www.ncbi.nlm.nih.gov/pubmed/15944694.

Kryndushkin, D.S., Alexandrov, I.M., Ter-Avanesyan, M.D., and Kushnirov, V. V (2003) Yeast $[\mathrm{PSI}+]$ prion aggregates are formed by small Sup35 polymers fragmented by Hsp104. J Biol Chem 278: 49636-49643 http://www.ncbi.nlm.nih.gov/pubmed/14507919.

Liebman, S.W., and Chernoff, Y.O. (2012) Prions in yeast. Genetics 191: 1041-1072 
http://www.ncbi.nlm.nih.gov/pubmed/22879407.

Liebman, S.W., and Derkatch, I.L. (1999) The yeast [PSI+] prion: making sense of nonsense. $J$ Biol Chem 274: $1181-1184$ http://www.ncbi.nlm.nih.gov/entrez/query.fcgi?cmd=Retrieve\&db=PubMed\&dopt=Citation\&list_ uids $=9880481$.

Liu, B., Larsson, L., Caballero, A., Hao, X., Öling, D., Grantham, J., and Nyström, T. (2010) The Polarisome Is Required for Segregation and Retrograde Transport of Protein Aggregates. Cell 140: 257-267 http://www.ncbi.nlm.nih.gov/pubmed/20141839.

Mathur, V., Taneja, V., Sun, Y., and Liebman, S.W. (2010) Analyzing the Birth and Propagation of Two Distinct Prions, [PSI+] and [Het-s]y, in Yeast. Mol Biol Cell 21: 1449-1461 http://www.ncbi.nlm.nih.gov/pubmed/20219972. Accessed September 20, 2017.

Matile, P., Cortat, M., Wiemken, A., and Frey-Wyssling, A. (1971) Isolation of glucanasecontaining particles from budding Saccharomyces cerevisiae. Proc Natl Acad Sci U S A .

McGlinchey, R.P., Kryndushkin, D., and Wickner, R.B. (2011) Suicidal [PSI+] is a lethal yeast prion. Proc Natl Acad Sci U S A 108: 5337-5341 http://www.ncbi.nlm.nih.gov/pubmed/21402947.

Newnam, G.P., Birchmore, J.L., and Chernoff, Y.O. (2011) Destabilization and recovery of a yeast prion after mild heat shock. $J$ Mol Biol 408: 432-448 http://www.ncbi.nlm.nih.gov/entrez/query.fcgi?cmd=Retrieve \&db=PubMed\&dopt=Citation\&list uids $=21392508$.

Novick, P., and Schekman, R. (1979) Secretion and cell-surface growth are blocked in a temperature-sensitive mutant of Saccharomyces cerevisiae. Proc Natl Acad Sci U S A 76: 18581862 http://www.ncbi.nlm.nih.gov/pubmed/377286.

Oliveira, D.L., Nakayasu, E.S., Joffe, L.S., Guimar??es, A.J., Sobreira, T.J.P., Nosanchuk, J.D., et al. (2010a) Characterization of yeast extracellular vesicles: Evidence for the participation of different pathways of cellular traffic in vesicle biogenesis. PLoS One 5: e11113 http://www.ncbi.nlm.nih.gov/pubmed/20559436.

Oliveira, D.L., Nakayasu, E.S., Joffe, L.S., Guimarães, A.J., Sobreira, T.J., Nosanchuk, J.D., et al. 
(2010b) Biogenesis of extracellular vesicles in yeast: Many questions with few answers. Commun Integr Biol 3: 533-535 http://www.ncbi.nlm.nih.gov/pubmed/21331232.

Palade, G. (1975) Intracellular aspects of the process of protein sy... [Science. 1975] - PubMed result. Science (80-) .

Patino, M.M., Liu, J.J., Glover, J.R., and Lindquist, S. (1996) Support for the prion hypothesis for inheritance of a phenotypic trait in yeast. Science (80- ) 273: 622-626 http://www.ncbi.nlm.nih.gov/pubmed/8662547.

Paushkin, S. V, Kushnirov, V. V, Smirnov, V.N., and Ter-Avanesyan, M.D. (1996) Propagation of the yeast prion-like [psi+] determinant is mediated by oligomerization of the SUP35-encoded polypeptide chain release factor. EMBO $J$ 15: 3127-3134 http://www.ncbi.nlm.nih.gov/pubmed/8670813.

Pelling, A.E., Sehati, S., Gralla, E.B., Valentine, J.S., and Gimzewski, J.K. (2004) Local nanomechanical motion of the cell wall of Saccharomyces cerevisiae. Science (80- ) 305: 11471150 http://www.ncbi.nlm.nih.gov/pubmed/15326353.

Reis, F.C.G., Borges, B.S., Jozefowicz, L.J., Sena, B.A.G., Garcia, A.W.A., Medeiros, L.C., et al. (2019) A Novel Protocol for the Isolation of Fungal Extracellular Vesicles Reveals the Participation of a Putative Scramblase in Polysaccharide Export and Capsule Construction in Cryptococcus gattii . mSphere.

Rodrigues, M.L., Nimrichter, L., Oliveira, D.L., Frases, S., Miranda, K., Zaragoza, O., et al. (2007) Vesicular polysaccharide export in Cryptococcus neoformans is a eukaryotic solution to the problem of fungal trans-cell wall transport. Eukaryot Cell 6: 48-59 http://www.ncbi.nlm.nih.gov/pubmed/17114598.

Sharma, J., Wisniewski, B.T., Paulson, E., Obaoye, J.O., Merrill, S.J., and Manogaran, A.L. (2017) De novo [PSI (+)] prion formation involves multiple pathways to form infectious oligomers. Sci Rep 7: 76 http://www.nature.com/articles/s41598-017-00135-6. Accessed September 20, 2017.

Tanaka, M., Chien, P., Naber, N., Cooke, R., and Weissman, J.S. (2004) Conformational variations in an infectious protein determine prion strain differences. Nature 428: 323-8 
http://www.ncbi.nlm.nih.gov/pubmed/15029196.

Ter-Avanesyan, M.D., Dagkesamanskaya, A.R., Kushnirov, V. V., and Smirnov, V.N. (1994) The SUP35 omnipotent suppressor gene is involved in the maintenance of the non-Mendelian determinant $\left[\mathrm{psi}^{+}\right]$in the yeast Saccharomyces cerevisiae. Genetics 137: 671-676 http://www.ncbi.nlm.nih.gov/entrez/query.fcgi? $\mathrm{cmd}=$ Retrieve $\& \mathrm{db}=\mathrm{PubMed} \& \mathrm{dopt}=\mathrm{Citation} \&$ list uids $=8088512$.

Tessarz, P., Schwarz, M., Mogk, A., and Bukau, B. (2009) The yeast AAA+ chaperone Hsp104 is part of a network that links the actin cytoskeleton with the inheritance of damaged proteins. Mol Cell Biol 29: 3738-3745 http://www.ncbi.nlm.nih.gov/pubmed/19398583.

Toyama, B.H., Kelly, M.J., Gross, J.D., and Weissman, J.S. (2007) The structural basis of yeast prion strain variants. Nature 449: 233-237 http://www.ncbi.nlm.nih.gov/pubmed/17767153.

True, H.L., Berlin, I., and Lindquist, S.L. (2004) Epigenetic regulation of translation reveals hidden genetic variation to produce complex traits. Nature 431: 184-187 http://www.ncbi.nlm.nih.gov/entrez/query.fcgi?cmd=Retrieve\&db=PubMed\&dopt=Citation\&list_ uids $=15311209$.

True, H.L., and Lindquist, S.L. (2000) A yeast prion provides a mechanism for genetic variation and phenotypic diversity. Nature 407: 483 http://www.ncbi.nlm.nih.gov/entrez/query.fcgi?cmd=Retrieve $\& \mathrm{db}=$ PubMed\&dopt=Citation\&list_ uids $=11028992$.

Tyedmers, J., Madariaga, M.L., and Lindquist, S. (2008) Prion switching in response to $\begin{array}{llllll}\text { environmental } & \text { stress. } & P L o S & \text { Biol } & \text { 6: } & \text { 2605-2613 }\end{array}$ http://www.ncbi.nlm.nih.gov/entrez/query.fcgi?cmd=Retrieve \&db=PubMed\&dopt=Citation\&list_ uids $=19067491$.

Uptain, S.M., Sawicki, G.J., Caughey, B., and Lindquist, S. (2001) Strains of [PSI(+)] are distinguished by their efficiencies of prion-mediated conformational conversion. EMBO $J \mathbf{2 0}$ : 6236-6245 http://www.ncbi.nlm.nih.gov/pubmed/11707395.

Walker, L., Sood, P., Lenardon, M.D., Milne, G., Olson, J., Jensen, G., et al. (2018) The viscoelastic properties of the fungal cell wall allow traffic of ambisome as intact liposome 
vesicles. MBio .

Wang, K., Melki, R., and Kabani, M. (2017) A prolonged chronological lifespan is an unexpected benefit of the $[\mathrm{PSI}+]$ prion in yeast. PLoS One 12: e0184905 http://www.ncbi.nlm.nih.gov/pubmed/28910422. Accessed September 18, 2017.

Wang, K., Melki, R., and Kabani, M. (2019) Growth phase-dependent changes in the size and infectivity of SDS-resistant Sup35p assemblies associated with the [PSI+] prion in yeast. $\mathrm{Mol}$ Microbiol.

Wickner, R.B., Edskes, H.K., Bateman, D., Kelly, A.C., and Gorkovskiy, A. (2011) The yeast prions [PSI+] and [URE3] are molecular degenerative diseases. Prion 5: 258-262 http://www.ncbi.nlm.nih.gov/pubmed/22052353.

Winters, C.M., Hong-Brown, L.Q., and Chiang, H.L. (2020) Intracellular vesicle clusters are organelles that synthesize extracellular vesicle-associated cargo proteins in yeast. $J$ Biol Chem 295: 2650-2663 http://www.ncbi.nlm.nih.gov/pubmed/31974164. Accessed March 23, 2020.

Wolf, J.M., and Casadevall, A. (2014) Challenges posed by extracellular vesicles from eukaryotic microbes. Curr Opin Microbiol 22: 73-78 http://www.ncbi.nlm.nih.gov/pubmed/25460799.

Zhao, K., Bleackley, M., Chisanga, D., Gangoda, L., Fonseka, P., Liem, M., et al. (2019) Extracellular vesicles secreted by Saccharomyces cerevisiae are involved in cell wall remodelling. Commun Biol .

Zhou, C., Slaughter, B.D., Unruh, J.R., Eldakak, A., Rubinstein, B., and Li, R. (2011) Motility and segregation of Hsp104-associated protein aggregates in budding yeast. Cell 147: 1186-1196 http://www.ncbi.nlm.nih.gov/pubmed/22118470.

Zhou, P., Derkatch, I.L., and Liebman, S.W. (2001) The relationship between visible intracellular aggregates that appear after overexpression of Sup35 and the yeast prion-like elements $[\mathrm{PSI}(+)]$ and $\quad[\mathrm{PIN}(+)]$ Mol $\quad$ Microbiol $\quad 37-46$ http://www.ncbi.nlm.nih.gov/entrez/query.fcgi?cmd=Retrieve \&db=PubMed\&dopt=Citation\&list uids $=11123686$.

Zhou, P., Derkatch, I.L., Uptain, S.M., Patino, M.M., Lindquist, S., and Liebman, S.W. (1999) 


\section{Figure legends}

Figure 1. Cell fractionation and isolation of periplasmic and extracellular vesicles from yeast cultures. This scheme describes the main methodological steps used to isolate periplasmic (PV) and extracellular (EV) vesicles from yeast cultures (see Materials and Methods and text for details).

Figure 2. PV and EV are differentially exported in response to glucose starvation. (A) PV and EV were isolated from 74-D694 cells grown for 3 days in YPDA medium containing 2\% or 0.5\% glucose, as indicated. The total protein content of each vesicle preparation was determined by the Bradford's assay and used as a proxy for vesicle yield in each condition (data represent the mean \pm SD of three independent vesicles preparations; inset: magnified portion of the graph for EV). (B) To account for their markedly different yields, PV and EV were respectively isolated from an equivalent of $\sim 1200$ and $\sim 12000 \mathrm{OD}_{600 \mathrm{~nm}}$ units of the same culture of $\left[\mathrm{PSI}^{+}\right]^{\mathrm{S}} 74-\mathrm{D} 694$ cells grown in $2 \%$ or $0.5 \%$ glucose. Vesicles were resuspended in the same volume of PBS. Thus, EV preparations were 10 times more concentrated than PV. Equal volumes of samples were analyzed by SDS-PAGE and Coomassie blue staining (upper panel) or by SDD-AGE followed by immunoblotting using anti-Sup35p antibodies (lower panel). (note: as shown in (A), the amount of EV isolated from glucose-starved cells was very low, and as a consequence the amount loaded on the gels was below the detection threshold for both Coomassie blue staining and immunoblotting).

Figure 3. Periplasmic and extracellular vesicles display similar round, ovoid or cup shapes. $\mathrm{PV}$ and EV vesicles purified from yeast cultures were visualized by negative-stain electron microscopy (scale bars: $100 \mathrm{~nm}$ ).

Figure 4. Periplasmic and extracellular vesicles have different size distributions. (A) The size distribution of PV and EV preparations was determined by analyzing electron micrographs such as those shown in Fig. 3 using the ImageJ software. Four independent PV and EV preparations were analyzed and combined, totalizing 5115 and 5059 vesicles, respectively. The size distribution of PVs and EVs was represented as boxplots showing median (middle line within each box), 25th (boxes lower boundaries) and 75th (boxes upper boundaries) percentiles, minimal and maximal 
values (whiskers), and outliers (dots). (B) PVs and EVs size distribution frequency histograms derived from the data in (A) (inset: magnified portion of the histogram between 200 and $600 \mathrm{~nm}$ ).

Figure 5. Glucose-starvation triggers a massive export of SDS-resistant Sup35p in the periplasm of $\left[\mathrm{psi}^{-}\right]$and $\left[\mathrm{PSI}^{+}\right]$74-D694 cells. Exponentially growing $\left[\mathrm{psi}^{-}\right],[\mathrm{PSI}]^{\mathrm{S}}$ and $\left[\mathrm{PSI}^{+}\right]^{\mathrm{W}}$ $74-D 694$ cells were inoculated in fresh YPDA medium containing $2 \%$ or $0.5 \%$ glucose and allowed to grow at $29^{\circ} \mathrm{C}$ under agitation. At the indicated time points, equal numbers of cells (as determined by measuring the optical density at $600 \mathrm{~nm}$ ) were removed and treated with $10 \mathrm{mM}$ sodium azide on ice. Cells were recovered by centrifugation at $3000 \mathrm{~g}$, flash frozen in liquid nitrogen and kept at $-80^{\circ} \mathrm{C}$. Cells were thawed and processed as described in Fig. 1 to obtain the intracellular (I) and total periplasm $\left(\mathrm{P}^{\mathrm{T}}\right)$ fractions. The samples were then analyzed by SDD-AGE (upper panel) or SDS-PAGE (middle and lower panels) followed by immunoblotting using antibodies against the indicated proteins.

Figure 6. Sup35p prion particles are localized within periplasmic vesicles.(A) Exponentially growing $\left[\mathrm{PSI}^{+}\right]^{\mathrm{S}} 74$-D694 cells were inoculated in fresh YPDA medium containing $0.5 \%$ glucose and allowed to grow for 3 days at $29^{\circ} \mathrm{C}$ under agitation. Cells were recovered and processed as described in Fig. 1 to obtain the intracellular $(\mathrm{I})$, total periplasm $\left(\mathrm{P}^{\mathrm{T}}\right)$, periplasmic vesicles $(\mathrm{PV})$ and soluble periplasmic $\left(\mathrm{P}^{\mathrm{S}}\right)$ fractions. Equal volumes of samples were analyzed by SDD-AGE and immunoblotting using anti-Sup35p antibodies. (B) A sample of PV (dashed gray box) was fixed with $2 \%$ paraformaldehyde, adsorbed onto electron microscopy grids, and permeabilized with $0.02 \%$ Triton X-100 for 10 min. Immunogold labeling of Sup35p was then performed using primary polyclonal anti-Sup35p antibody and secondary anti-rabbit 10-nm-gold-conjugated antibodies. Electron microscopy grids were fixed with $1 \%$ glutaraldehyde for $5 \mathrm{~min}$ at room temperature and visualized by negative-stain electron microscopy (scale bars, $100 \mathrm{~nm}$; arrowheads point to gold-labeled Sup35p-positive vesicles).

Figure 7. Glucose starvation does not affect prion propagation. The prion phenotypes of [psi $\left.{ }^{-}\right]$, $\left[P S I^{+}\right]^{\mathrm{S}}$ and $\left[\mathrm{PSI}^{+}\right]^{\mathrm{W}} 74$-D694 cells was determined onto $1 / 4$-YPD plates containing $2 \%$ or $0.5 \%$ glucose, as indicated. 
Figure S1. The glucose concentration in the growth medium does not significantly affect the size distribution of PV and EV. The size distribution of PVs and EVs (same as in Fig. 3) was represented as boxplots showing median (middle line within each box), 25th (boxes lower boundaries) and 75th (boxes upper boundaries) percentiles, minimal and maximal values (whiskers), and outliers (dots). Data represent two independent PV and EV preparations per growth condition that were combined for the analysis, totalizing $\sim 2500$ vesicles per condition.

Figure S2. Growth of $\left[p s i^{-}\right],\left[P S I^{+}\right]^{\mathrm{S}}$ and $\left[\mathrm{PSI}^{+}\right]^{\mathrm{W}}$ 74-D694 cells in $2 \%$ or $0.5 \%$ glucose. Cells were inoculated in fresh YPDA medium containing $2 \%$ or $0.5 \%$ glucose and allowed to grow at $30^{\circ} \mathrm{C}$ under agitation. Aliquots were periodically removed and the optical density at $600 \mathrm{~nm}$ measured. Data points are the mean of three independent cultures \pm SE (error bars are within the variables symbols).

Figure S3. PV isolated from $\left[\mathrm{PSI}^{+}\right]$cells contain infectious Sup35p particles. PV isolated from $\left[p s i^{-}\right]$or $\left[\mathrm{PSI}^{+}\right]^{\mathrm{S}}$ cells, as indicated, were transformed into [psi-] 74-D694 spheroplasts. Random clones from each transformation reaction were patched onto $1 / 4$-YPD plates (insets) to assess their prion phenotype and to determine the $\left[\mathrm{PSI}^{+}\right]$induction frequencies (data represent the mean $\pm \mathrm{SD}$ of two transformations with independent PV preparations; transformation with [psi $i^{-} \mathrm{PV}$ did not yield any $\left[\mathrm{PSI}^{+}\right]$clones, and the $\left[\mathrm{PSI}^{+}\right]$induction frequency was then equal to 0 ).

\section{Figure S4. Lyticase digestion of yeast cell walls allows the release of Sup35p-containing} periplasmic vesicles. (A) Scheme describing the methodological steps used to isolate PV from yeast cells treated with lyticase. Exponentially growing $\left[\mathrm{PSI}^{+}\right]^{\mathrm{S}} 74-\mathrm{D} 694$ cells were inoculated in fresh YPDA medium containing $2 \%$ or $0.5 \%$ glucose and allowed to grow for 3 days at $29^{\circ} \mathrm{C}$ under agitation. Equal numbers of cells were removed from the cultures, washed once in water, and then resuspended in spheroplasting solution with or without lyticase, as indicated. After a 30 min incubation at $30^{\circ} \mathrm{C}$, spheroplasts were recovered by centrifugation at $800 \mathrm{~g}$ for $5 \mathrm{~min}$. The supernatant -representing the total periplasmic $\left(\mathrm{P}^{\mathrm{T}}\right)$ material released after lyticase digestion of the cell walls- was centrifuged at 100,000 g for 70 min to obtain the periplasmic vesicles (PV). (B) A sample of PV obtained by lyticase treatment (gray dashed box) were fixed with 2\% paraformaldehyde and visualized by negative-stain electron microscopy (scale bars, $100 \mathrm{~nm}$ ). (C)

Equal amounts of PV were analyzed by SDS-PAGE and immunoblotting using anti-Sup35p and anti-Pgk1p antibodies, as indicated.

This article is protected by copyright. All rights reserved 
yeast cultures $\left(29^{\circ} \mathrm{C}\right)$ :

- YPDA containing $2 \%$ glucose

- YPDA containing $0.5 \%$ glucose

1

centrifugation: $5 \mathrm{~min}$ at $2,000 \mathrm{~g}$

cell pellet

1- periplasm extraction: Tris.Cl pH $9.4+\beta$-mercaptoethanol $\left(37^{\circ} \mathrm{C}\right)$

2- centrifugation: $5 \mathrm{~min}$ at $3,000 \mathrm{~g}$ (RT)

extracted cell pellet

1- cell lysis: glass-beads beating (on ice) 2- centrifugation: $2 \mathrm{~min}$ at $4,000 \mathrm{~g}\left(4^{\circ} \mathrm{C}\right)$

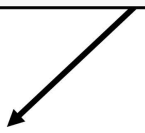

Intracellular fraction (I)
1- filtration: $0.22 \mu \mathrm{m}$

2- centrifugation: $70 \mathrm{~min}$ at $100,000 \mathrm{~g}\left(4^{\circ} \mathrm{C}\right)$

Soluble Periplasmic fraction $\left(\mathrm{P}^{\mathrm{S}}\right)$
Periplasmic

Vesicles (PV) conditioned medium

1- filtration: $0.22 \mu \mathrm{m}$

2- centrifugation: $70 \mathrm{~min}$ at $100,000 \mathrm{~g}\left(4^{\circ} \mathrm{C}\right)$

3- centrifugation: $15 \mathrm{~min}$ at $10,000 \mathrm{~g} \mathrm{(4^{ \circ } \mathrm { C } )}$

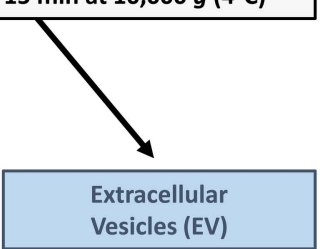


glucose: $0.5 \% \quad 2 \%$ $\overline{\text { PVEV PVEV }}$
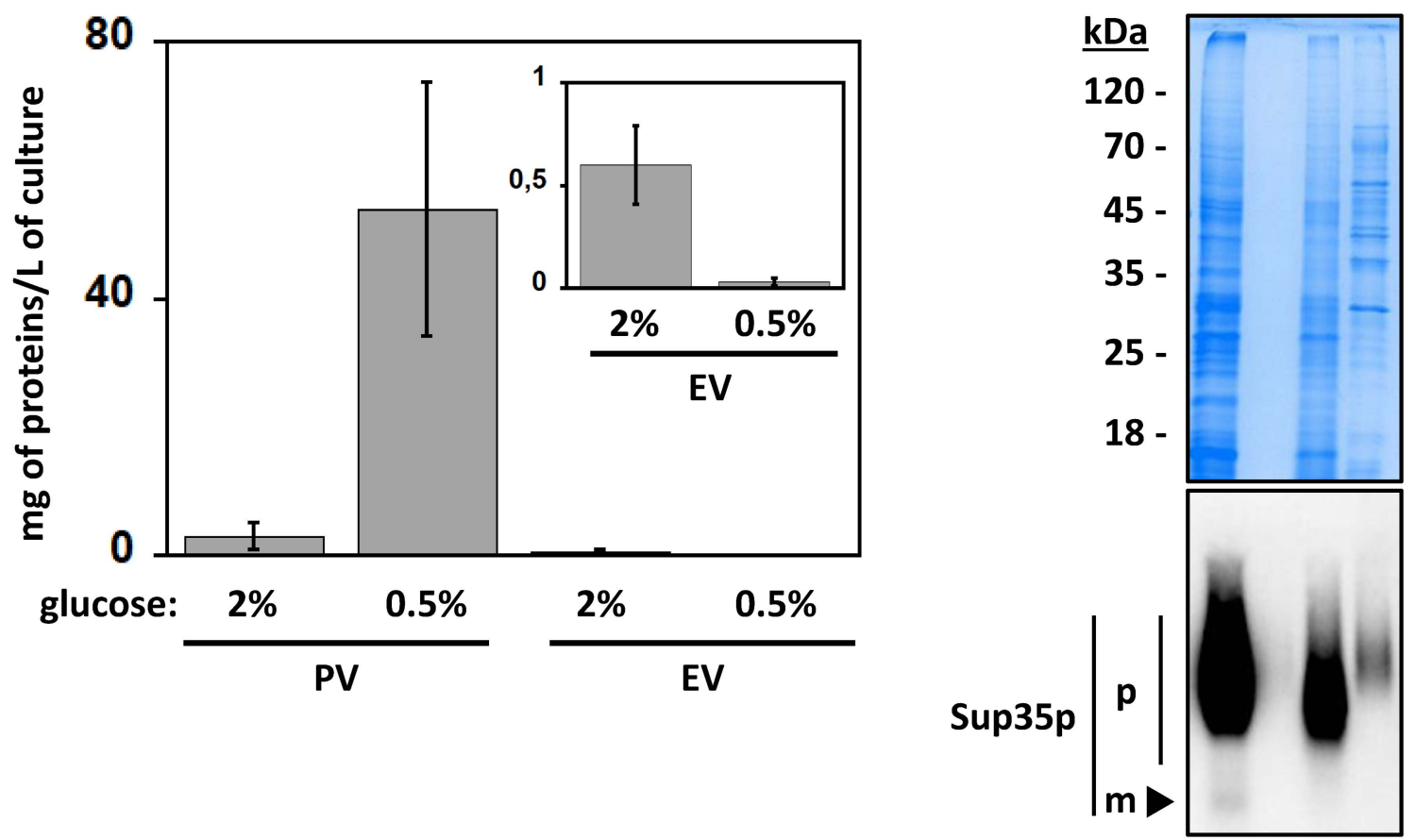

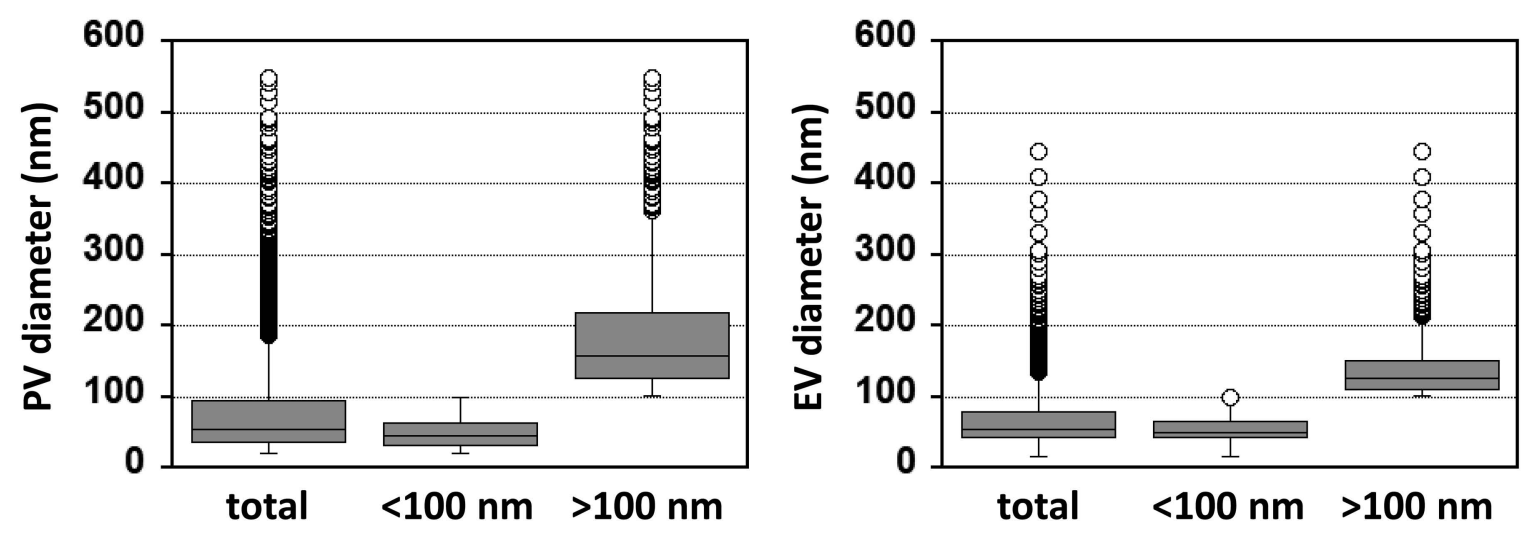

B
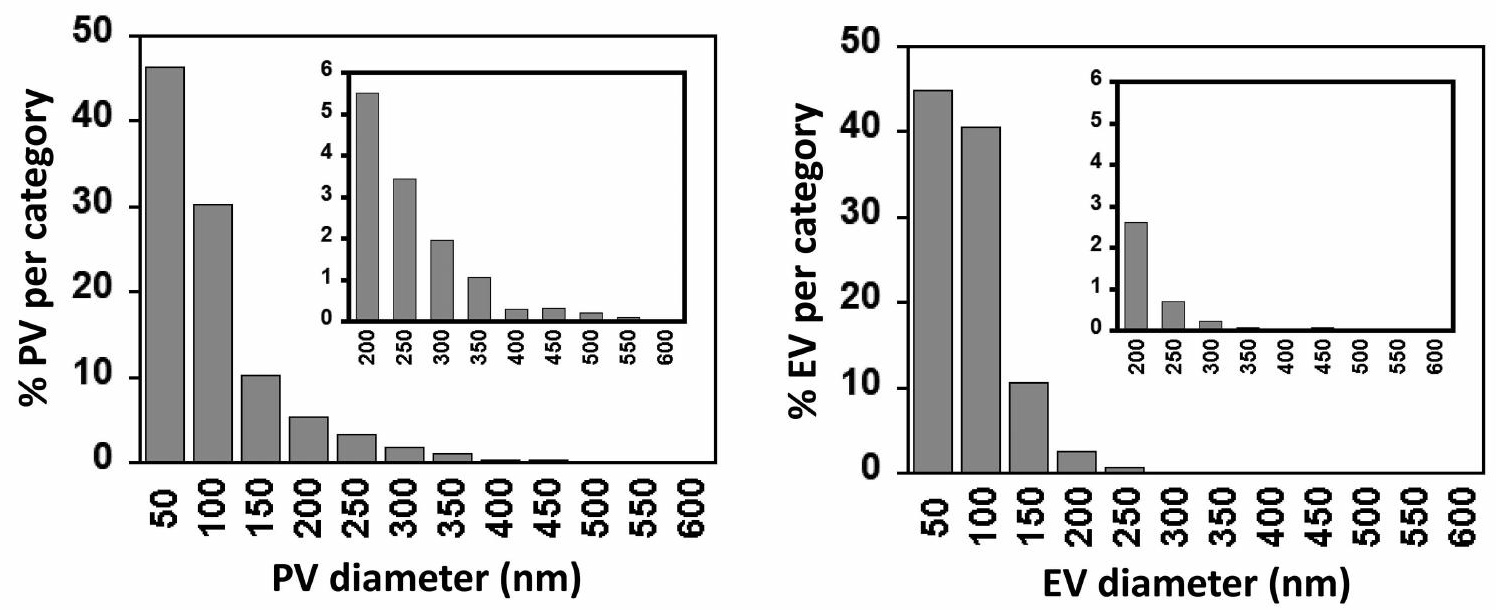

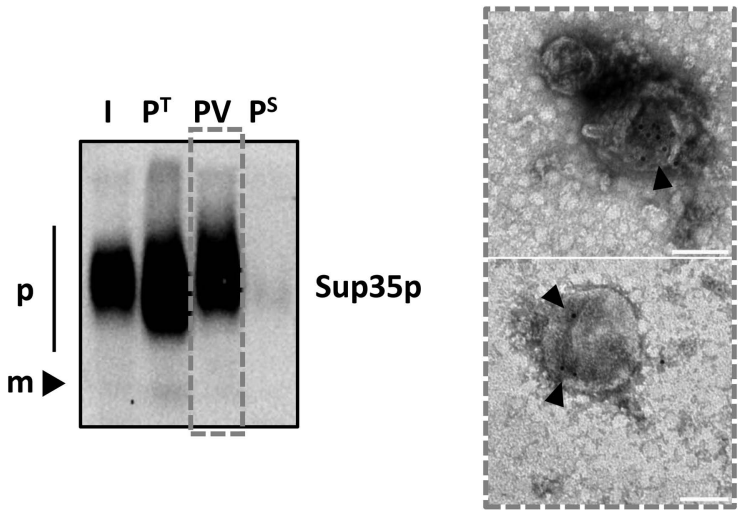


\section{$2 \%$ glucose}

$0.5 \%$ glucose

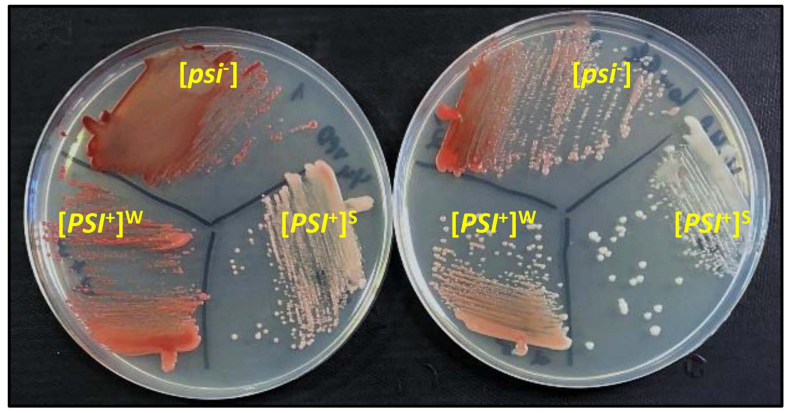

